\title{
Control del ácaro Varroa destructor en cría sellada de obrera al utilizar ácido fórmico y timol, en colmenas de abejas africanizadas, bajo condiciones tropicales. Nota Técnica.
}

\section{Control of Varroa destructor mites in capped worker brood cells by using formic acid and thymol in africanized honey bee colonies under tropical conditions. A technical note}

\section{Marianyela Ramírez, Rafael A. Calderón}

Programa Integrado de Patología Apícola, Centro de Investigaciones Apícolas Tropicales, Universidad Nacional, Heredia, Costa Rica. Correos electrónicos: marianyela.ramirez.montero@una.cr I

rafael.calderon.fallas@una.cr

Recibido: 16 de Marzo de 2016 Corregido: 6 de Octubre de 2016 Aceptado: 14 de Octubre de 2016

Resumen: Se evaluó la mortalidad del ácaro Varroa destructor en cría sellada de obrera, al aplicar ácido fórmico y timol en colmenas de abejas africanizadas. El apiario se ubicó en Atenas, Alajuela - Costa Rica. Este se dividió en tres grupos seleccionados al azar (A, B y C). El grupo A fue tratado con $150 \mathrm{~g}$ de ácido fórmico al 65\%; en el B se realizó dos aplicaciones de $25 \mathrm{~g}$ de timol; el C se utilizó como testigo. La mortalidad de los diferentes estadios de varroa fue evaluada en cría sellada de obrera, revisando la pupa y el fondo de la celda. Se determinó una mortalidad de $86 \%$ en los diferentes estadios de varroa en cría sellada de obrera luego de aplicar ácido fórmico. Mientras que en colmenas tratadas con timol y el grupo testigo, la muerte de ácaros, en cría sellada, fue menor a un $10 \%$. Se concluye que, al aplicar ácido fórmico, se produce una alta mortalidad de los diferentes estadios del ácaro $V$. destructor en la cría sellada de obrera. Mientras tanto, en las colmenas tratadas con timol y el grupo testigo, la mortalidad de ácaros fue considerablemente menor, lo cual puede indicar un efecto directo del ácido fórmico sobre los ácaros presentes en la cría sellada de obrera.

Palabras clave: acido fórmico, timol, Varroa destructor, abejas africanizadas, cría sellada

Abstract: The mortality of the Varroa destructor mite was evaluated in capped worker brood cells by using formic acid and thymol in Africanized honey bee colonies. The apiary was located in Atenas, Alajuela, Costa Rica, and was randomly arranged in three groups: A, B and C. Group A was treated with $150 \mathrm{~g}$ formic acid at $65 \%$, while group B received two applications of $25 \mathrm{~g}$ thymol, and group $C$ was used as a control group. Mortality of the Varroa's different stages was evaluated in capped worker brood cells by checking the pupa and the bottom of the cell for mites. Eighty-six percent mite mortality occurred in capped brood cells in colonies treated with formic acid, while Varroa mortality was less than $10 \%$ in capped cells for control colonies and colonies treated with thymol. In conclusion, high mortality of Varroa mites was observed in capped brood cells after applying formic acid, while mortality was low in control colonies and colonies treated with thymol. The foregoing could imply a direct effect of formic acid over mites in capped brood cells.

Keywords: formic acid, thymol, Varroa destructor, Africanized honeybees, sealed brood cells 


\section{Introducción}

La Varroosis es una de las enfermedades parasitarias de mayor incidencia económica en la apicultura; causada por el ácaro Varroa destructor, el cual parasita tanto a la cría como las abejas adultas (Espina \& Ordetx 1984). Este ácaro se alimenta de la hemolinfa de las abejas (larvas, pupas y adultos), lo cual ocasiona una serie de trastornos como: bajo peso corporal, deformación de alas y abdomen, pérdida de proteínas de la hemolinfa, disminución en el período de pecoreo, entre otros (Botta et al. 2004). Sin embargo, el daño más perjudicial, ocasionado por el ácaro varroa, es la transmisión de agentes virales, como el virus que deforma las alas, el virus Kashmir y el virus de la parálisis aguda, los cuales ocasionan un debilitamiento de la colmena y, en ciertos casos, la pérdida (Bailey \& Ball 1991; Ritter 2001).

En las abejas adultas, los ácaros pueden encontrarse en el abdomen, por debajo de los esternitos abdominales, donde se alimentan de la hemolinfa de la abeja (fase forética) (Bailey 1984; Vandame 2000). Se reproducen exclusivamente en la cría sellada, tanto de obrera como de zángano (Vandame 2000; Ritter 2001). Para llevar a cabo su reproducción, el ácaro ingresa a una celda con cría unas horas antes de ser sellada y, una vez sellada la celda, se desplaza hacia la pupa donde se alimenta e inicia su fase reproductiva (Vandame 2000; Ritter 2001). Por tanto, dentro de la celda, varroa se encuentra protegido de la mayoría de acaricidas, debido a que estos actúan únicamente sobre los ácaros presentes en las abejas adultas, lo cual podría considerarse como una limitante para el tratamiento, dado que aumenta el período de aplicación de los productos (el producto debe permanecer más tiempo en la colmena) (Koeniger \& Fuchs 1988).

Existen diversos acaricidas para el control de la Varroosis, entre ellos el ácido fórmico (ácido orgánico), presente en otros insectos como las hormigas y el timol (aceite esencial), sustancia natural derivada de la planta del tomillo, ambos productos considerados orgánicos y de bajo impacto ambiental (Eguaras et al. 2003; Adamczyk et al. 2005; Bogdanov 2006). A la fecha, se ha señalado que el ácido fórmico es el único producto que elimina los ácaros, los cuales se encuentran sobre las abejas adultas y los que se están reproduciendo en el interior de las celdas con cría sellada (Calis et al. 1998). Sin embargo, la efectividad del ácido fórmico y el timol en el tratamiento de varroa ha sido estudiada, principalmente, en abejas de tipo europeo, en países con condiciones de clima templado; mientras que, la investigación en abejas africanizadas y en condiciones tropicales es muy escasa (Eguaras et al. 2003; Baggio et al. 2004; Gregorc \& Planinc 2005; Satta et al. 2005). Por tanto, el objetivo de este estudio consiste en determinar la mortalidad del ácaro Varroa destructor en celdas con cría sellada de obrera al aplicar ácido fórmico y timol, en colmenas de abejas africanizadas bajo condiciones tropicales.

\section{Materiales y Métodos}

Ubicación geográfica: El estudio se realizó en un apiario experimental constituido por 16 colmenas de abejas africanizadas (Apis mellifera), ubicado en el Cantón de Atenas, provincia de Alajuela-Costa Rica. Este se llevó a cabo de junio a octubre (época lluviosa), meses en 
los cuales hay una mayor incidencia del ácaro varroa, (nivel elevado de infestación en las colmenas) (Calderón et al. 2007).

Productos evaluados: En el estudio se evaluaron los productos MAQS ${ }^{\circledR}$ (ácido fórmico) y Apiguard ${ }^{\circledR}$ (timol) en el control del ácaro varroa en cría sellada de obrera.

a. El producto MAOS ${ }^{\circledR}$ consiste en un gel orgánico formulado en tiras de $150 \mathrm{~g}$, con ácido fórmico al $65 \%$, las cuales se colocan sobre los marcos de la cámara de cría.

b. El acaricida Apiguard ${ }^{\circledR}$ es un gel que contiene timol al $25 \%$ (Vita-Europe). Una de sus presentaciones comerciales es en paquetes de $25 \mathrm{~g}$.

Descripción de los tratamientos: El apiario se dividió en tres grupos seleccionados al azar $(A, B$ y $C)$, conformados por ocho, cinco y tres colmenas, respectivamente.

Grupo A: estas colmenas fueron tratadas con el producto MAOS ${ }^{\circledR}$. Se aplicó una tira (150 g) por colmena, la cual se dividió en dos partes, colocadas diagonalmente sobre los marcos de la cámara de cría y separadas por una distancia de $25 \mathrm{~cm}$ entre ellas. A cada colmena se colocó un marco de madera en la parte superior, para proporcionar un espacio de $1,0 \mathrm{~cm}$ entre el gel y la tapa. Se realizó una sola aplicación del producto, el cual permaneció en la colmena durante cuatro semanas, aún cuando, en la mayoría de casos, la evaporación se completó en la segunda semana.

Grupo B: Las colmenas del grupo B fueron tratadas con el producto Apiguard ${ }^{\circledR}$. A cada colmena se aplicó un paquete de $25 \mathrm{~g}$ de gel en una lámina de cartulina de $12 \times 9$ $\mathrm{cm}$ colocada sobre los marcos de la cámara de cría. Se realizó dos aplicaciones de Apiguard ${ }^{\circledR}$; la primera el día uno; la segunda el día 15. El tratamiento completo fue de $50 \mathrm{~g}$ de Apiguard ${ }^{\circledR}$ por colmena, con una duración de 30 días. Adicionalmente, a cada colmena se adaptó un marco de madera en la parte superior, el cual proporcionó un espacio de $1,0 \mathrm{~cm}$ entre el producto y la tapa, facilitando la evaporación del timol. Además, este espacio permitió, a las obreras, tener contacto con el gel, el cual se adhiere al cuerpo de la abeja y, mientras realiza diversas actividades, lo distribuye en la colmena. Asimismo, por el comportamiento de limpieza, otras obreras participan en la remoción del timol contribuyendo a su dispersión.

Grupo C: este grupo de colmenas se utilizó como testigo, evaluando la mortalidad natural de ácaros, por lo que no se aplicó producto alguno.

Mortalidad de los ácaros en la cría sellada: Se analizó la mortalidad del ácaro madre y su descendencia (protoninfa, deutoninfa, macho y hembra), en cría sellada de obrera. Se tomó una muestra de panal $(10 \times 5 \mathrm{~cm})$ con cría sellada de obrera, proveniente de colmenas tratadas con ácido fórmico, timol y colmenas del grupo testigo. Las muestras se colectaron a las 24 y 72 horas, luego de iniciados los tratamientos se trasladaron al laboratorio de Patología Apícola para su análisis. Se removió el opérculo de la celda, utilizando una pinza de punta fina. Se retiró la pupa de la celda y se colocó en una placa de petri. Utilizando una lupa con fuente de luz, se revisó cuidadosamente el fondo de la celda, para determinar la presencia de ácaros (maduros e inmaduros). Con la finalidad de determinar la condición 
(mortalidad) de los diferentes estadios, los ácaros encontrados se retiraron de la celda y se examinaron usando un estereoscopio (10x).

Para cada celda analizada, se registró la etapa de desarrollo de la pupa de la abeja, el total de ácaros adultos, así como la cantidad y el estadio de desarrollo de la cría (en ciertos casos se encontró más de un ácaro madre por celda= sobreinfestación). Para clasificar la etapa de desarrollo (estadios maduros e inmaduros), se tomó como referencia el desarrollo ontogénico señalado por Martin (1995). Los diferentes estadios del ácaro se clasificaron como protoninfa, deutoninfa, macho e hija adulta (Ifantidis 1997).

La mortalidad de los diferentes estadios del ácaro se comprobó según los parámetros indicados por Ifantidis (1997):

Un ácaro (cualquier estadio) no es viable si presenta deformaciones o alteraciones en el cuerpo. Por ejemplo, se observan deshidratados y con apariencia plegada.

Los estadios móviles (protoninfa móvil, deutoninfa móvil, macho, hija adulta y ácaro adulto) que no presenten movimiento en las extremidades, son considerados muertos.

La mortalidad de los estadios inmóviles, especialmente la deutoninfa, se establece por la pérdida de movimiento peristáltico en los túbulos de Malpighi (se revisaron en el estereoscopio, aumento $7 x$ ). En condiciones normales, los túbulos se encuentran bien formados y son visibles a través del integumento.

La muerte de la deutoninfa inmóvil durante el proceso de muda, es reconocida por la ausencia de movimiento de las extremidades, las cuales se observan contraídas contra el opistosoma.

Si la muerte del ácaro ocurre al final del proceso de muda (hija adulta), se observa una remoción incompleta de la cutícula (exuvia).

\section{Resultados}

Luego de aplicar ácido fórmico, se determinó una mortalidad del 95\% del ácaro madre en la cría sellada de obrera $(n=307)$. Esta mortalidad se registró tanto a las $24 \mathrm{~h}$, como a las $72 \mathrm{~h}$ después de la aplicación del producto. Al analizar la mortalidad del macho de varroa $(n=61)$, se encontró que un $84 \%$ estaban muertos, siendo uno de los estadios que presentó mayor mortalidad luego de aplicar ácido fórmico. Por otra parte, el estadio en el que se observó menor mortalidad fue la deutoninfa con un $41 \%$ ( $n=51$ ) (Cuadro 1).

En las colmenas tratadas con timol, se determinó una baja mortalidad del ácaro madre, observándose la mayoría en buenas condiciones. Solamente un $9 \%$ de los ácaros en celdas de obrera, evaluados a las $24 \mathrm{~h}$ y $72 \mathrm{~h}$ posteriores a la primera y segunda aplicación del timol, se encontró muerto. Igualmente, la mayoría de protoninfas y deutoninfas se encontraba en condiciones viables, siendo la mortalidad menor al $10 \%$. Por otra parte, se presentó un $33 \%$ de mortalidad en las hembras (hijas adultas) (Cuadro 1). 
En las colmenas testigo ocurrió mortalidad del ácaro madre y su descendencia, aunque en una proporción menor, al compararlas con las colmenas que se aplicó ácido fórmico. La mortalidad natural del ácaro madre correspondió a un $7 \%(n=391)$, mientras que en los estadios inmaduros y las hembras, fue menor al $6 \%$. Sin embargo, la mayor mortalidad se presentó en el macho (Cuadro 1).

Cuadro 1. Mortalidad de los diferentes estadios del ácaro varroa en celdas con cría sellada de obrera, en colmenas tratadas con ácido fórmico y timol, y las colmenas del grupo testigo.

\begin{tabular}{lccc}
\hline \multicolumn{1}{c}{ Estadio ácaro } & Acido fórmico (\%) & Timol (\%) & Testigo (\%) \\
\hline Madres & 95 & 9 & 7 \\
Protoninfas & 88 & 9 & 5 \\
Deutoninfas & 41 & 6 & 5 \\
Hembras & 78 & 33 & 6 \\
Machos & 84 & 11 & 16 \\
\hline
\end{tabular}

Se debe indicar que, en los tres grupos de colmenas se observó mortalidad de ácaros (maduros e inmaduros) en la cría sellada. Sin embargo, esta mortalidad fue considerablemente mayor en las colmenas a las cuales se aplicó ácido fórmico (Figura 1), en las cuales más del 85\% de los ácaros (maduros e inmaduros) se encontraban muertos $(n=616)$. Mientras que, en las colmenas tratadas con timol $(n=137)$ y en el grupo testigo $(n=723)$, la mortalidad fue inferior al 10\% (Figura 1).

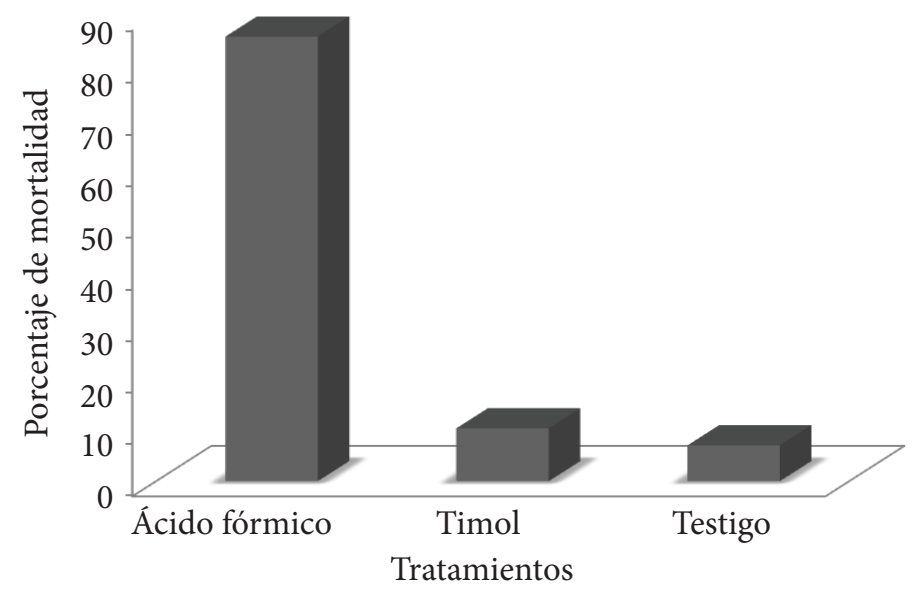

Figura 1. Mortalidad del ácaro varroa en celdas con cría sellada de obrera al aplicar ácido fórmico, timol y el grupo testigo. 


\section{Discusión}

Se ha señalado que el ácido fórmico es el único acaricida capaz de controlar los ácaros que se encuentran sobre las abejas adultas y los que se están reproduciendo en el interior de las celdas con cría sellada (Calis et al. 1998; Calderón et al. 2000). Algunos autores indican que el vapor del ácido fórmico atraviesa el opérculo de la celda, debido a que la molécula del ácido es más pequeña que el poro del opérculo, lo cual provoca la muerte de los ácaros que se encuentran en el interior (Eguaras et al. 2001).

En este estudio, al aplicar ácido fórmico, se determinó una alta mortalidad de los diferentes estadios de varroa en la cría sellada de obrera, principalmente del ácaro madre, lo cual reduce el nivel de infestación en las colmenas. Asimismo, limita la alimentación de los estadios inmaduros de varroa, dado que el sitio sobre la pupa del cual se alimentan lo establece y lo mantiene activo el ácaro madre, y es utilizado por los estadios de protoninfa y deutoninfa (móviles), cuyo aparato bucal no les permite perforar la cutícula de la pupa y establecer un nuevo sitio (Donzé \& Guerin 1994).

Se debe resaltar el rápido efecto del ácido fórmico sobre varroa, porque, al revisar las celdas, 24 horas después de su aplicación, se determinó una mortalidad evidente de ácaros. Esto corresponde con lo observado por Calderón et al. (2000) y Van Alten et al. (2009), quienes indicaron una alta mortalidad de varroa en la cría sellada tres días después de su aplicación.

Por otra parte, se determinó una alta mortalidad del macho de varroa. Debido a que el apareamiento de las hijas ocurre exclusivamente durante ese ciclo reproductivo en la cría sellada, la muerte temprana del macho va a aumentar la cantidad de hembras infértiles en la población de varroa, pues estas hembras ingresan a una celda con cría pero no se reproducen (Martin et al. 1997).

A la fecha, no hay estudios que indiquen un efecto directo del timol sobre los ácaros que se están reproduciendo en la cría sellada. Esto corresponde con lo observado en este estudio. Se determinó una baja mortalidad del ácaro madre y su descendencia en la cría sellada (inferior al 10\%), luego de utilizar el timol, lo cual es similar a la mortalidad ocurrida de forma natural. Algunos autores señalan que uno de los principales mecanismos de acción del Apiguard ${ }^{\circledR}$, es por medio del comportamiento social de las abejas, las cuales entran en contacto con el producto, lo distribuyen al resto de la colmena y de esta manera entra en contacto con los ácaros presentes en las abejas adultas (Baggio et al. 2004; Palmeri et al. 2007).

En cuanto a la mortalidad de ácaros en el grupo de colmenas testigo, se puede mencionar que, en condiciones naturales, ocurre muerte de ácaros en la cría sellada, tanto del ácaro madre como de su descendencia. Esta mortalidad puede relacionarse con la competencia que se da entre los diferentes estadios por alcanzar el sitio de alimentación en la pupa, afectando principalmente los estadios inmaduros (Martin 1994). Asimismo, se menciona que el tamaño de la celda de obrera afecta la viabilidad de la cría inmadura, debido a que el espacio disponible es limitado (Donzé \& Guerin 1994). En el macho, se determinó el mayor porcentaje de mortalidad natural, la cual podría deberse a la falta de alimento, pues algunos autores indican que el aparato bucal del macho está modificado para la transferencia de espermatozoides y no es utilizado para la alimentación (Ritter 2001). De acuerdo con 
Martin et al. (1997), los estadios del ácaro que no logra ubicar el sitio de alimentación o no lo utiliza, eventualmente muere. Además, como se mencionó, la muerte del macho podría aumentar la población de hembras infértiles de varroa, debido a que el apareamiento de las hijas ocurre durante el ciclo reproductivo en la celda sellada.

Se puede considerar que el control de ácaros en la cría sellada por efecto del ácido fórmico es una ventaja con respecto a otros productos como el timol, dado que limita la alimentación de varroa en la pupa, previniendo la transmisión y activación de uno de los principales virus que afecta a las abejas, el virus que deforma las alas, el cual puede causar la pérdida de la colmena (Bailey y Ball 1991).

\section{Conclusión}

Se concluye que, al aplicar ácido fórmico en las colmenas, se alcanzó una alta mortalidad de los diferentes estadios del ácaro $V$. destructor en la cría sellada de obrera, siendo el ácaro madre y el macho, los estadios con mayor mortalidad. Mientras que, en las colmenas tratadas con timol y el grupo testigo, la mortalidad de ácaros en la cría sellada fue considerablemente menor. Lo cual indica un efecto directo del ácido fórmico sobre los ácaros presentes en la cría sellada de obrera.

\section{Agradecimientos}

Deseamos agradecer a David VanderDussen, representante de NOD Apiary Products Ltd. - Canadá por la donación del MAOS para evaluación. Asimismo, a Guillermo Ramírez Arias, por la colaboración en el manejo de las colmenas del CINAT durante el estudio.

\section{Referencias}

Adamczyk, S., Lázaro, R., Pérez-Arquillué, C., Conchello, P. \& Herrera, A. 2005. Evaluation of residues of essential oil components in honey after different anti-Varroa treatments. J. Agric. Food Chem. 53: 10085-10090.

Baggio, A., Arculeo, P., Nanetti, A., Marinelli, E. \& Mutinelli, F. 2004. Field trials with different thymol-based products for the control of Varroosis. Am. Bee J. 144: 395-400.

Bailey, L. 1984. Patología de las abejas. Acribia, Zaragoza, ES. 139 p.

Bailey, L. \& Ball, B. 1991. Honey Bee Pathology. 2 ed. Academic Press, Londres, Reino Unido.193 p.

Bogdanov, S. 2006. Contaminants of bee products. Apidologie 37: 1-18.

Botta, E., Carmenate, H. \& De la Torre, P. 2004. Varroasis peligrosa enfermedad de la abeja melífera. Fitosanidad 1: 73-79.

Calderón, R., Ortiz, R., Arce, H., Van Veen, J. \& Ouan, J. 2000. Effectiveness of formic acid on varroa mortality in capped brood cells of Africanized honey bees. J. Apic. Res. 39: 177-179. 
Calderón, R., Fallas, N. \& Sánchez, L. 2007. Detección de enfermedades en abejas Africanizadas en Costa Rica. Cien. Vet. 25: 335-348.

Calis, J., Boot, W., Beetsma, J., Van Den Eijnde, J., Ruijter, A. \& Van Der Steen, J. 1998. Control of varroa combining trapping in honey bee worker brood with formic acid treatment of the capped brood outside the colony: putting knowledge on brood cell invasion into practice. J. Apic. Res. 37: 205-215.

Donzé, G. \& Guerin, P. 1994. Behavioral attributes and parental care of varroa mites parasiting honey bee brood. Behav. Ecol. Sociobiol. 34: 305-319.

Eguaras, M., Labattaglia, M., Faverin, C., Del Hoyo, M., Palacio, M., Carrin, A., Ruffinengo, S. \& Bedascarrabure, E. 2001. Varroa jacobsoni control with formic acid used in different application ways in subtropical and temperate climates. Apiacta 36: 97-101.

Eguaras, M., Palacio, M., Faverin, C., Basualdo, M., Del Hoyo, M., Velis, G. \& Bedascarrasbure, E. 2003. Efficacy of formic acid in gel for varroa control in Apis mellifera L.: importance of the dispenser position inside the hive. Vet. Parasitol. 111: 241-245.

Espina, D. \& Ordetx, G. 1984. Apicultura tropical. Tecnológica de Costa Rica, Cartago, CR. 506 p.

Gregorc, A. \& Planinc, I. 2005. The control of Varroa destructor in honey bee colonies using the thymol-based acaricide- Apiguard. Am. Bee J. 145: 672-675.

Ifantidis, M. 1997. Ontogenesis of VarroajacobsoniOud. EnCahiers Options Méditerranéennes. Varroosis in the Mediterranean region. CIHEAM, Zaragosa, ES. p 13-21.

Koeniger, N. \& Fuchs, S. 1988. Control of Varroa jacobsoni Oud. in honeybee colonies containing sealed brood cells. Apidologie 19: 117-130.

Martin, S. 1994. Ontogenesis of the mite Varroa jacobsoni Oud. in worker brood of the honeybee Apis mellifera L. under natural conditions. Exp. Appl Acarol. 18: 87-100.

Martin, S. 1995. Ontogenesis of the mite Varroa jacobsoni Oud. in drone brood of the honeybee Apis mellifera L. under natural conditions. Exp. Appl. Acarol. 19: 199-210.

Martin, S; Holland, K. \& Murray, M. 1997. Non-reproduction in the honey bee mite Varroa jacobsoni in honey bee (Apis mellifera) colonies. J. Apic. Res. 36: 113-123.

Palmeri, V; Campolo, 0.\& Zappala, L. 2007. Evaluation of two methods for applying Apiguard ${ }^{\circledR}$ in an area with continuous nectar flows and brood rearing. J. Apic. Res. 46: 105-109.

Ritter, W. 2001. Enfermedades de las abejas. Acribia, Zaragoza, ES. 146 p.

Satta, A., Floris, I., Eguaras, M., Cabras, P., Garau, V. \& Melis, M. 2005. Formic acid-based treatments for control of Varroa destructor in a mediterranean area. J. Econ. Entomol. 98: 267-273.

Van Alten, A., Tam, J. \& Kempers, M. 2009. Winter colony health assessment after using Mite Away ${ }^{\mathrm{TM}}$ Quick Strip $\left(\mathrm{MAOS}^{\mathrm{TM}}\right)$ as a control for varroa mites in the fall of 2009. Ontario Beekeepers association, CA. 5 p.

Vandame, R. 2000. Control alternativo de varroa en apicultura. El Colegio de la Frontera Sur (ECOSUR). Chiapas, MX. 30 p. 